\title{
Muscle Atrophy and Artery Shrinkage of Residual Limb After Trans-Femoral Amputation: A Morphological Study
}

\author{
RUI-QI DONG \\ Sichuan University
}

TAO-PING BAI

Sichuan University

YANG LIU ( $\square$ liuyangecho@163.com )

Sichuan University

\section{Research Article}

Keywords: Amputation, residual limb, muscle atrophy, arterial shrinkage, morphological study, prosthesis

Posted Date: February 8th, 2021

DOI: https://doi.org/10.21203/rs.3.rs-156345/v1

License: (1) This work is licensed under a Creative Commons Attribution 4.0 International License.

Read Full License 


\section{Abstract}

Aim. After limb amputation, patients will face many complex postoperative problems. The pathogeny of these problems usually involves blood circulation disorders, vascular lesions and other angioneurotic issues. The correlation between blood flow/vessels and those residual limb problems like the most prevalent muscle atrophy is very importent.

Method. Through the case study of eight unilateral trans-femoral amputees, this research performed the morphological index analysis of residual limb muscle atrophy, arterial shrinkage and their potential correlations.

Results. The atrophy level of muscles and the shrinkage level of arteries were different. Overall, Different muscles have different atrophy. Compared with the prosthesis users, those cases without using prosthesis exhibited more severe muscle atrophy and arterial shrinkage in their residual limbs. For the correlation between muscle atrophy and arterial shrinkage on the basis of blood supply relationship, there was a positive correlation expressed only in the cases using prosthesis.

Conclusion: Using a prosthesis could not only effectively achieve the functional compensation for residual limb, but also promote a joint adaptation of the muscular and arterial physiological state of both the sound and amputated limbs to the new gait pattern and body balance, as well as rehabilitation process.

\section{Introduction}

Amputation is defined as the removal of a limb, appendage or outgrowth of body, when the part completely lose function and activity or cause death threats. After amputation, the long-term disabilityoriented treatment which plays a key role in improving function and returning the patient to normal life is also worthy of great attention. World Health Organization estimated that the worldwide disabled population proportion is about $10 \%$. In 2005 , the number of people with limb loss in the United States was estimated to be 1.6 million, and the growth rate of this figure was predicted to be remarkable [1]. In China, according to the main data bulletin of the Second National Sample Survey on Disability released in 2006, the total number of people with disabilities is 82.96 million, of which an amount of 2.26 million amputees. On this basis, the Wenchuan earthquake in 2008 has considerably increased this figure.

As regards amputation site and level, upper limb amputation takes up $8.3 \%$, whereas lower limb amputation accounts for $91.7 \%$, among which $53.8 \%$ is trans-tibial and $32.6 \%$ is trans-femoral amputation [2]. Diabetes and its complications, arteriosclerosis obliterans, thromboangiitis obliterans, arterial thrombosis and other peripheral vascular occlusive diseases [3-5], as well as malignant bone tumor are prone to attack lower limbs and lead to the fatal results which are irreparable by revascularization, drug control or other means, such as gangrene. Unfortunately, amputation is not once and for all. Some of those vascular diseases would continue to damage the residual limb resulting in secondary or even multiple surgeries [6], or producing a high incidence of complications (34.4\%) [7]. In 
fact, even if the danger of original diseases is completely removed, amputees will still face many complex postoperative problems which are difficult to avoid. According to clinical experience, patients are usually beset by blisters, swelling, pressure ulcers and other skin problems [8, 9], deep tissue injury [10], distal osteophyte or bony spur [11, 12], painful neuroma and phantom limb pain [13], as well as residual limb muscle atrophy which is the most prevalent issue [14]. The pathogeny of these problems usually involve blood circulation disorders, vascular lesions and other angioneurotic issues. This indicates the necessity to consider the impact of vascular structure and hemodynamic state on the rehabilitation situation of residual limb, as well as the correlation between blood flow/vessels and those residual limb problems. Nevertheless, most of the existing researches concerned vascular diseases and above various problems separately. Another aspect, since thigh muscles are rich and the loss of function caused by trans-femoral amputation is more than trans-tibial, the disuse atrophy of thigh muscles would be more serious than that of calf muscles. Actually, some studies have demonstrated this phenomenon [15]. Therefore, the present study intends to perform the morphological investigation about the arterial shrinkage and muscle atrophy of both residual limb and sound limb after unilateral trans-femoral amputation, and to preliminarily describe the correlation between the variation of arteries and muscles.

\section{Methods}

The ethical approval for this case study was granted by the Human Subjects Ethics Subcommittee of The Hong Kong Polytechnic University (the reference number is HSEARS20130828002), and all methods were performed in accordance with the relevant guidelines and regulations. Informed consent was obtained from each subject involved in this study. The cooperation institution is West China Hospital, Sichuan University.

\subsection{Subjects}

Depending on the purpose and pilot property of this study, inclusion criteria were as follows: 1 . unilateral trans-femoral amputees (no preference for left or right); 2. aged between 18 to 60 years old and either gender; 3. middle or lower thigh amputation; 4. received a good immediate postoperative treatment, implying a normal initial muscle state. Exclusion criteria included: 1 . amputation accompanied by other vascular surgery; 2 . there was still lower limb peripheral vascular diseases; 3 . obvious damage in the skin and soft tissue of residual limb; 4. completely lost the ability of the locomotor activity of lower limbs due to the injuries of brain or other part of body. Since treatment may be not dissimilar among different amputation causes [1], this study did not set any specific etiology as an inclusion or exclusion criterion. In addition, based on clinical experience, whether patients wear a prosthesis or not, muscle atrophy would almost inevitably occur, so the usage of prosthesis was an alternative instead of a filter. As for the length of time since surgery, the maximum term expected was three years, in order to minimize the influence of other problems which may emerge over time on muscles and vessels.

17 qualified patients were selected from a total of 291 amputation cases of the Orthopaedics of West China Hospital in the 2010-2013 period. After a detailed explanation about all the information of this 
study by phone contact, 8 subjects were recruited eventually, including 2 follow-up cases. Their ages ranged from 20 to 48 years old, 2 females and 6 males. 3 subjects walked on crutches instead of using prosthesis, and the other 5 subjects started to wear prosthesis for walking from different time. When they participated in this study, the time since amputation ranged from 10 to 33 months. The 2 follow-up patients were examined for three times in the convalescence phase which was defined as the first year after operation [14], and the interval was four months. Information for these 8 subjects has been described in Table 1.

Table 1

Subject information.

\begin{tabular}{|lllllll|}
\hline Subject & Gender & Age & $\begin{array}{l}\text { Operative } \\
\text { site }\end{array}$ & $\begin{array}{l}\text { Amputation } \\
\text { reason }\end{array}$ & $\begin{array}{l}\text { Ambulation } \\
\text { mode }\end{array}$ & $\begin{array}{l}\text { Time since } \\
\text { amputation }\end{array}$ \\
\hline Case-1 & Female & 20 & $\begin{array}{l}\text { Middle left } \\
\text { thigh }\end{array}$ & Bone tumour & Prosthesis & $\begin{array}{l}\text { Follow-up within the } \\
\text { 1st year }\end{array}$ \\
\hline Case-2 & Male & 43 & $\begin{array}{l}\text { Middle left } \\
\text { thigh }\end{array}$ & Bone tumour & Crutches & $\begin{array}{l}\text { Follow-up within the } \\
\text { 1st year }\end{array}$ \\
\hline Case-3 & Male & 28 & $\begin{array}{l}\text { Middle left } \\
\text { thigh }\end{array}$ & Bone tumour & Crutches & 10 months \\
\hline Case-5 & Male & 28 & $\begin{array}{l}\text { Lower right } \\
\text { thigh }\end{array}$ & Trauma & Prosthesis & 30 months \\
Case-6 & Male & 48 & $\begin{array}{l}\text { Middle right } \\
\text { thigh }\end{array}$ & Trauma & Crutches & 16 months \\
Middle right & Bone tumour & Prosthesis & 33 months \\
\hline Case-7 & Male & 46 & $\begin{array}{l}\text { Lower left } \\
\text { thigh }\end{array}$ & Trauma & Prosthesis & 31 months \\
\hline Case-8 & Female & 43 & $\begin{array}{l}\text { Lower left } \\
\text { thigh }\end{array}$ & Trauma & Prosthesis & 16 months \\
\hline
\end{tabular}

\subsection{Measurements}

Each subject was arranged to receive his/her Computed Tomography (CT) angiography and MRI scan of both thighs on the same day to obtain the three dimensional (3D) images of vessels and the horizontal images of muscles. The two follow-up patients received these two examinations at the 4th, 8th and 12th months after surgery. CT images and Magnetic Resonance Imaging (MRI) images carried the unit information $(\mathrm{mm})$. After clinical data collection, the medical image processing software MIMICS v10.0 (Materialize, Belgium) was employed to carry out the 3D reconstruction of the arterial tree of residual limb and sound limb separately from CT images. After modeling, the arterial measurement section of both thighs was defined from the top of caput femoris to residual bone end (Fig. 1.(a)). That means the sound limb arteries were cut off at the contralateral bone end. Then MedCAD module was used to achieve the format conversion from scanned data to computer-aided design (CAD) data by generating the control 
points and center lines of vascular trees (resolving resolution and the distance between control points are $1.0 \mathrm{~mm}$, and the number of iterations is 2), thus the geometrical parameters of each artery could be exported for describing its morphological properties. Meanwhile, the software ImageJ 1.49j (National Institutes of Health, MD, USA) was applied to select the MRI slices at three different levels, $30 \%, 50 \%$ and $70 \%$ of the residual limb length, which is commonly defined from ischial tuberosity to the end of residual limb (Fig. 1.(b)). Subsequently, the muscle measurements of bilateral limb from these slices were performed by manual operation of polygon selections and automatic area calculation.

\subsection{Indicators}

According to the physiological structure of thigh, this study selected common femoral artery (CFA), superficial femoral artery (SFA), deep femoral artery (DFA), the descending branch of lateral femoral circumflex artery (LFCA), and medial femoral circumflex artery (MFCA) as the objectives of vascular research (Fig. 1.(c)). As for muscles, rectus femoris (RF), vastus medialis (VM), vastus intermedius (VI), vastus lateralis (VL), sartorius (SART), gracilis (GRAC), adductor longus (AL), adductor magnus (AM), semimembranosus (SEMI_M), semitendinosus (SEMI_T), and the long head of biceps femoris (BF) were selected to be measured individually (Fig. 1.(d)). The morphological indicators of these five main arteries are the mean values of their hydraulic diameter (Dh), circumference (Scf) and cross-sectional area (CSA) exported by MIMICS, as well as their ratio of residual limb to sound limb through simple calculation. While the indicators of muscles are the CSA of the above mentioned eleven separate muscles and their bilateral ratio. In addition, the total CSA ratio of all muscles to thigh and its bilateral difference, as well as the residual limb length, were also measured and calculated for analysis and discussion.

\section{Results}

\subsection{Muscles}

The CSA and its residual/sound limb ratio of each muscle at different levels were used to indicate the degree of muscle atrophy. Those measurement data and the calculated ratios were organized as the following charts in order to visually demonstrate the numerical results. Figure 2.(a), Fig. 2.(b) and Fig. 2. (c) are respectively Case-1's follow up measurement results of the muscle CSA at $30 \%, 50 \%$ and $70 \%$ level. The corresponding results at different levels of Case-2 are shown in Fig. 2.(d), Fig. 2.(e) and Fig. 2. (f). The 6 non-follow-up cases' measurement results are shown in Fig. 3.(a) (Case-3), Fig. 3.(b) (Case-4), Fig. 3.(c) (Case-5), Fig. 3.(d) (Case-6), Fig. 3.(e) (Case-7), and Fig. 3.(f) (Case-8).

The ratios of total muscle area to thigh area of bilateral limb at different levels are shown in Table 2 (2 follow-up cases) and Table 3 (the other 6 cases). The total muscle area included adductor brevis and the short head of biceps femoris, which were not been individually compared. The absolute and relative length of residual limb of each case are shown in Table 4 ( 2 follow-up cases) and Table 5 (the other 6 cases). 
Table 2

The muscle/thigh total area ratios of bilateral limb at 3 levels of 2 follow-up cases.

\begin{tabular}{|c|c|c|c|c|c|c|c|}
\hline \multirow{2}{*}{\multicolumn{2}{|c|}{$\begin{array}{l}\text { Muscle/thigh } \\
\text { Total area ratio }\end{array}$}} & \multicolumn{3}{|l|}{ Case-1 } & \multicolumn{3}{|l|}{ Case-2 } \\
\hline & & \multirow{2}{*}{$\begin{array}{l}\text { Sound } \\
\text { limb } \\
44.47 \%\end{array}$} & \multirow{2}{*}{$\begin{array}{l}\text { Residual } \\
\text { limb } \\
31.44 \%\end{array}$} & \multirow{2}{*}{$\begin{array}{l}\begin{array}{l}\text { Bilateral } \\
\text { difference }\end{array} \\
13.03 \%\end{array}$} & \multirow{2}{*}{$\begin{array}{l}\text { Sound } \\
\text { limb } \\
50.96 \%\end{array}$} & \multirow{2}{*}{$\begin{array}{l}\text { Residual } \\
\text { limb } \\
46.67 \%\end{array}$} & \multirow{2}{*}{$\begin{array}{l}\begin{array}{l}\text { Bilateral } \\
\text { difference }\end{array} \\
4.29 \%\end{array}$} \\
\hline 4 & upper & & & & & & \\
\hline & middle & $48.27 \%$ & $33.34 \%$ & $14.93 \%$ & $57.49 \%$ & $49.46 \%$ & $8.03 \%$ \\
\hline & lower & $48.04 \%$ & $29.94 \%$ & $18.10 \%$ & $58.28 \%$ & $42.38 \%$ & $15.90 \%$ \\
\hline \multirow{3}{*}{$\begin{array}{l}8 \\
\text { months }\end{array}$} & upper & $42.66 \%$ & $30.03 \%$ & $12.63 \%$ & $49.21 \%$ & $44.19 \%$ & $5.02 \%$ \\
\hline & middle & $45.71 \%$ & $32.06 \%$ & $13.65 \%$ & $55.17 \%$ & $45.39 \%$ & $9.79 \%$ \\
\hline & lower & $46.45 \%$ & $27.88 \%$ & $18.57 \%$ & $56.45 \%$ & $41.95 \%$ & $14.49 \%$ \\
\hline \multirow{3}{*}{$\begin{array}{l}12 \\
\text { months }\end{array}$} & upper & $42.53 \%$ & $31.58 \%$ & $10.95 \%$ & $46.49 \%$ & $40.87 \%$ & $5.62 \%$ \\
\hline & middle & $46.26 \%$ & $33.23 \%$ & $12.43 \%$ & $53.12 \%$ & $42.65 \%$ & $10.47 \%$ \\
\hline & lower & $45.03 \%$ & $28.35 \%$ & $16.68 \%$ & $56.75 \%$ & $37.52 \%$ & $19.23 \%$ \\
\hline
\end{tabular}


Table 3

The muscle/thigh total area ratios of bilateral limb at 3 levels of the nonfollow-up cases.

\begin{tabular}{|c|c|c|c|c|}
\hline \multicolumn{2}{|c|}{$\begin{array}{l}\text { Muscle/thigh } \\
\text { Total area ratio }\end{array}$} & Sound limb & Residual limb & Bilateral difference \\
\hline \multirow[t]{3}{*}{ Case-3 } & upper & $75.01 \%$ & $58.64 \%$ & $16.37 \%$ \\
\hline & middle & $76.12 \%$ & $58.44 \%$ & $17.68 \%$ \\
\hline & lower & $73.02 \%$ & $48.02 \%$ & $25.00 \%$ \\
\hline \multirow[t]{3}{*}{ Case-4 } & upper & $58.74 \%$ & $45.09 \%$ & $13.65 \%$ \\
\hline & middle & $61.68 \%$ & $47.41 \%$ & $14.28 \%$ \\
\hline & lower & $60.02 \%$ & $43.21 \%$ & $16.81 \%$ \\
\hline \multirow[t]{3}{*}{ Case-5 } & upper & $74.13 \%$ & $65.14 \%$ & $8.99 \%$ \\
\hline & middle & $76.93 \%$ & $62.98 \%$ & $13.95 \%$ \\
\hline & lower & $78.33 \%$ & $53.42 \%$ & $24.91 \%$ \\
\hline \multirow[t]{3}{*}{ Case-6 } & upper & $66.83 \%$ & $58.61 \%$ & $8.21 \%$ \\
\hline & middle & $67.87 \%$ & $58.13 \%$ & $9.74 \%$ \\
\hline & lower & $68.98 \%$ & $53.39 \%$ & $15.59 \%$ \\
\hline \multirow[t]{3}{*}{ Case-7 } & upper & $51.33 \%$ & $43.60 \%$ & $7.73 \%$ \\
\hline & middle & $57.48 \%$ & $42.90 \%$ & $14.58 \%$ \\
\hline & lower & $57.38 \%$ & $41.06 \%$ & $16.33 \%$ \\
\hline \multirow[t]{3}{*}{ Case-8 } & upper & $35.11 \%$ & $28.89 \%$ & $6.21 \%$ \\
\hline & middle & $37.20 \%$ & $26.44 \%$ & $10.76 \%$ \\
\hline & lower & $37.66 \%$ & $20.34 \%$ & $17.33 \%$ \\
\hline
\end{tabular}


Table 4

The residual limb length and bilateral length ratio of 2 follow-up cases.

\begin{tabular}{|llll|}
\hline Length and bilateral ratio & Case-1 & Case-2 \\
\hline \multirow{3}{*}{4 months } & Residual limb length $(\mathrm{mm})$ & 161.44 & 196.44 \\
\cline { 2 - 4 } & Bilateral length ratio & $54.04 \%$ & $56.73 \%$ \\
\hline \multirow{2}{*}{8 months } & Residual limb length $(\mathrm{mm})$ & 161.25 & 193.91 \\
\cline { 2 - 4 } & Bilateral length ratio & $53.98 \%$ & $55.99 \%$ \\
\hline \multirow{2}{*}{12 months } & Residual limb length $(\mathrm{mm})$ & 158.18 & 190.06 \\
\cline { 2 - 4 } & Bilateral length ratio & $52.95 \%$ & $54.88 \%$ \\
\cline { 2 - 4 } & & & \\
\cline { 2 - 4 }
\end{tabular}

Table 5

The residual limb length and bilateral length ratio of the non-follow-up cases.

\begin{tabular}{|lllllll|}
\hline Length and bilateral ratio & Case-3 & Case-4 & Case-5 & Case-6 & Case-7 & Case-8 \\
\hline Residual limb length $(\mathrm{mm})$ & 208.63 & 256.17 & 167.64 & 121.68 & 221.56 & 188.43 \\
\hline Bilateral length ratio & $58.32 \%$ & $75.71 \%$ & $47.59 \%$ & $39.27 \%$ & $69.36 \%$ & $60.77 \%$ \\
\hline
\end{tabular}

\subsection{Arteries}

Unit information $(\mathrm{mm})$ comes with the enhanced CT images, which were imported to MIMICS v10.0 for the 3D reconstruction of blood vessels to generate the control points and center lines of vascular trees. The control point parameters series of the 5 main arteries, including 3D coordinates, hydraulic diameter, circumference and cross-sectional area, were exported by MedCAD module (resolving resolution and the distance between control points are $1.0 \mathrm{~mm}$, and the number of iterations is 2.). Through these data, the mean values and the residual/sound limb ratio of these arterial morphological indicators of each case were calculated, and then were organized as the following charts. Figure 4.(a) and Fig. 4.(b) are respectively Case-1's and Case-2's follow up measurement results of the 5 main arteries. The 6 nonfollow-up cases' results are shown in Fig. 4.(c) (Case-3), Fig. 4.(d) (Case-4), Fig. 4.(e) (Case-5), Fig. 4.(f) (Case-6), Fig. 4.(g) (Case-7), and Fig. 4.(h) (Case-8). In these figures, the left y axis is used to measure the Dh ( $\mathrm{mm})$, Scf $(\mathrm{mm})$ and CSA ( $\mathrm{mm} 2)$, and the right y axis measures the residual/sound ratio of the three indicators (Dh\%, Scf\%, CSA\%). The gray part (Dif) means absolute difference between residual limb and sound limb.

\section{Discussion}

\subsection{Muscle atrophy}

As can be seen from Fig. 2.(a) to Fig. 3.(f), the CSA residual/sound limb ratio of each muscle is not identical at the three different levels. This could be ascribed to the anatomic shape and relative position 
of each muscle, and the residual limb length which means the amputation level of each case (shown in Table 4 and Table 5). In addition, in the adaptation process of new muscle state and movement pattern, the changes of body balance and dissymmetrical gait, as well as the increase of walking energy consumption, would lead to different degrees of muscle atrophy [16]. For the two follow-up cases, the CSA residual/sound limb ratio of each muscle varies within the first year after amputation. And Case-1's magnitude of changes is smaller than Case-2's (shown in Fig. 2.(a) to Fig. 2.(f)). This may be caused by their different ambulation modes (Case- 1 wears a prosthesis and Case-2 uses crutches), exercise amount/frequency, gait adjustment and so on.

In spite of the muscle changes of the 8 cases are different, in general quadriceps in anterior muscle group show the greatest atrophy, and wherein vastus medialis and vastus lateralis are the most significant. Oppositely, the long head of biceps femoris and semimembranosus in posterior muscle group, as well as gracilis in medial muscle group show the minimal atrophy. Moreover, at the upper and middle levels of some cases, semimembranosus and gracilis even show no atrophy, which means their CSA of the residual limbs are greater than those of the sound limbs. Atrophy of quadriceps could be explained by the attached joints and kinematic features of thigh muscles. Proximal rectus femoris attaches to pelvis, so it can act on both hip and knee joints. Yet proximal vastus medialis, vastus intermedius and vastus lateralis only attach to femur and their main attachment joint is knee, so they are strong extensor but single movement function. Trans-femoral amputees lost their knee, which means the extension of quadriceps is greatly reduced, therefore could cause the loss of muscle strength and atrophy. As for hamstrings, originating from ischial tuberosity and distal end attaching on knee, connect hip and knee joints, so they are involved in various movement forms of the two joints. When people are in a comfortable symmetrical standing, in virtue of the function of quadriceps, adductors and gluteus, hamstrings are inactive. But when any action that lead to deviation from the hip axis and weight forward occurs, hamstrings would immediately contract strongly. After amputation, the standing and walking postures of patients are no longer symmetric. In the process of gait adaptation and looking for new balance, it may cause the compensatory hyperfunction of residual limb hamstrings, and also extremely active flexion to compensate for the loss of knee function [17], thereby ensuring the normal thickness of flexors. When people are in a sitting position, hamstrings also participate in the activities of pelvis to maintain trunk upright and the overall body balance. Generally, the sitting and lying time of amputees is longer than standing or walking time. Due to the lack of sustaining and strength of the foot and knee, hamstrings may need to play more synergy in the hip to support the activities of waist and residual limb. From a biomechanical point of view to analyze, after amputation, the great changes of the anatomical structure of residual limb induce variations on muscle physiological tension and movement form. While hamstrings replace triceps surae as the major muscles for propulsion, and also ensure the good contact between residual limb and prosthetic socket [16]. Therefore, the atrophy degree of the hamstrings of residual limb is relatively small, or even not atrophy but greater CSA than sound limb in some cases. This could also be summarized by the theory of use and disuse.

From Table 2 and Table 3 can be seen, the bilateral differences of muscle/thigh total area ratio increase gradually from the upper to the lower level, especially Case-3 and Case-5 who do not use a prosthesis, 
and their bilateral differences at the lower level up to $25.00 \%$ and $24.91 \%$. This could also be explained by the changes in the physiological tension and movement form of these muscles. The upper muscles are closer to hip joint and likely play their function of movement more than the muscles at middle and lower levels, for example, the adductor group that connect anterior pelvis and femur and cross through hip joint, as well as the posterior muscle group whose proximal end attaches to pelvis (ischial tuberosity). While the lower muscles lose their movement function substantially in the case of not use a prosthesis. In addition, the lower level is close to the residual bone end, where the coated muscles are less and the intermuscular adipose tissue is more [15]. Therefore the distal muscles of residual limb may be more prone to lose attachment points, get muscle tension decline, slide or retract at the bone end due to the different treatment of muscles during the surgery. Similarly, as shown in Table 2 and Table 4, comparing the follow-up results of the muscle/thigh total area ratio and the residual/sound limb length ratio of Case1 and Case-2, although both the bilateral muscle area and the residual limb length of them decreased, the decrement of Case- 1 who use a prosthesis for daily walk is less than Case-2 without the use of a prosthesis. And the bilateral difference of muscle/thigh total area ratio of Case- 1 is getting smaller, while that bilateral difference of Case-2 gradually increases. It illustrates that using a prosthesis to maximize the movement function of residual limb and to increase patient's activity could slow down the muscle atrophy of both sides. Comparing those area and length ratios of six non-follow-up cases from Table 3 and Table 5, whether wearing a prosthesis or not, their muscle atrophy extents of residual limb are proportional to the residual limb length. Admittedly, this is related to the selection of horizontal levels for CSA measurement, and affected by patients' gait coordination, the starting time of using a prosthesis since amputation, walking/exercise amount and frequency by the prosthesis and many other factors, but it also indicates that muscle atrophy in the section closer to hip is slighter, while in the section closer to residual bone end is greater. As regards the relation between muscle atrophy and the time after surgery, it does not reflect a consistent trend from the eight cases in this study. This may be owing to the individual differences in the use of prosthesis, activity amount and other factors above mentioned.

\subsection{Arterial shrinkage}

As shown in Fig. 4.(a) and Fig. 4.(b), the mean values of the hydraulic diameter (Dh), circumference (Scf) and cross-sectional area (CSA) of the five main arteries of two follow-up cases showed changes in values and fluctuations in residual/sound limb ratio in different examination time. That means within a year after the amputation, not only residual limb muscle states have not been fully mature, arteries and blood flow has not yet achieved complete stability. In terms of the arterial CSA which could directly reflect blood flow volume, Case-1's magnitude of changes of residual/sound limb ratio is smaller than Case-2's, and that is corresponding to the volatility of muscle CSA in the follow-up period.

As can be seen from Fig. 4.(a) to Fig. 4.(h), although the situation is not the same in all cases, overall, the shrinkage of superficial femoral artery is most obvious, which means its CSA residual/sound limb ratio is the lowest, followed by lateral and medial femoral circumflex arteries, while the minimum shrinkage shows in deep femoral artery. These general trends could be explained by the blood supply of lower limb. Because trans-femoral amputation results in the loss of most part of the affected side, the total amount 
of blood supply required by residual limb is far less than that of sound limb, therefore the blood flow and lumen CSA of common femoral artery significantly reduce. However, the branches of it also include superficial epigastric artery, superficial/deep iliac circumflex artery, and superficial/deep external pudendal artery and so on, so its shrinkage would not be too serious. The lowest lumen CSA residual/sound limb ratio of common femoral artery is $45.62 \%$ in 8 cases. As the two main branches of common femoral artery, superficial femoral artery and deep femoral artery show different shrinkage situation. Since numerous muscular arteries originate from the deep femoral artery which is the most important blood supply to the thigh muscles, and its three perforator branches mainly deliver blood to the adductor group and the posterior muscle group with lesser extent atrophy, furthermore, the nutrient arteries of femur often originate from its perforator too, the shrinkage of the blood flow and lumen CSA of deep femoral artery is relatively minor. As for superficial femoral artery, which from the femoral triangle goes down into adductor canal and crosses the adductor hiatus to popliteal fossa (then renamed popliteal artery), its distal branches including descending genicular artery, saphenous artery and some joint muscular arteries mainly supply blood to vastus medialis, adductor magnus and knee joint, while its middle and upper muscular branches mainly supply blood to sartorius, vastus lateralis and adductors. In the residual limb, the loss of popliteal artery makes the blood flow of superficial femoral artery greatly reduce. At the same time, those main branches concentrating in the lower part of thigh close to knee joint are also lost. Moreover, the atrophy degrees of its blood supply objects vastus medialis, adductor magnus and sartorius are relatively high. These may be the reasons why the shrinkage of the superficial femoral artery of residual limb is serious. Normally, the lumen diameter and CSA of superficial femoral artery are significantly greater than that of deep femoral artery, but due to the above reasons, there are five cases show the opposite result about the CSA of these two arteries in their residual limb, and these two CSA values of the other three cases are very close. As for the shrinkage of medial femoral circumflex artery and the descending branch of lateral circumflex femoral artery, there are differences in individual cases, and the specific discussion is in the below comparative analysis of the morphological changes in muscles and arteries.

Comparing Case-2 (Fig. 4.(b)), Case-3 (Fig. 4.(c)) and Case-5 (Fig. 4.(e)) who do not use a prosthesis, and the other five cases (Fig. 4.(a), 4.(d), 4.(f), 4.(g), 4.(h)) who wear a prosthesis, it can be seen that prosthesis users' residual/sound limb ratios of the each index of five main arteries are in general higher than those of the cases without using a prosthesis, indicating that the total blood flow of the residual limb of prosthesis users is larger. This result corresponds to the prosthesis-motivating difference in muscle atrophy. As regards the relations between arterial shrinkage and the time after surgery, as well as the residual limb length, there is no consistent trend showed from the eight cases in this study. Similar to muscle atrophy, it may be owing to the individual differences in many factors involved in daily exercise or blood diseases.

\subsection{Correlation between morphological changes of arteries and muscles}


In a separate focus on muscle or artery changes, through the comparative analysis between cases could find some broadly consistent trends. But in consideration of the case differences caused by multiple factors, the internal correspondence analysis of each case based on the artery-muscle blood supply relationship is needed to illustrate whether there is a definite correlation between their morphological changes in residual limb.

Comparing Case-2, Case- 3 and Case -5 who use crutches for daily walking and Case-1, Case-4, Case- 6 , Case-7, and Case-8 who wear a prosthesis, the former three cases exhibit more serious muscle atrophy and arterial shrinkage in their residual limb, with larger atrophy degree gap between muscles, but similar shrinkage extent of each artery; in contrast, the latter five cases show milder muscle atrophy and arterial shrinkage, with relatively average atrophy degree of each muscle, but greater shrinkage extent gap between arteries. On the basis of the blood supply relationship, for the cases wearing a prosthesis, they exhibit lesser shrinkage of deep femoral artery and medial femoral circumflex artery, and their medial muscles (adductors and gracilis) and hamstrings which are mainly fed by these two arteries show lighter atrophy degree; meanwhile, they exhibit greater shrinkage of superficial femoral artery and lateral femoral circumflex artery, and their quadriceps mainly fed by these two arteries show larger atrophy degree. That is to say, from the results of these five cases, a positive correlation between muscle atrophy and arterial shrinkage of the residual limb could be summed up. However, there is no clear expression of this positive correlation in the other three cases without wearing a prosthesis and even opposite results like that, the shrinkage of their medial femoral circumflex arteries is relatively significant, but the gracilis or hamstrings mainly fed by this artery show very small degree of atrophy or even no atrophy but reverse increase. This could be interpreted as that, without using a prosthesis, the compensatory hyperfunction of hamstrings caused by playing synergistic role in hip joint or participating in femur activities, does not increase the blood flow of medial femoral circumflex artery considerably, nor prevent its shrinkage. To observe the two follow-up cases, within one year after surgery, Case-1's CSA residual/sound limb ratio of each muscle shows smaller amplitude of change, and her bilateral difference of muscle/thigh total area ratio gradually decreases. The results of Case- 2 are on the contrary, and the shortening degree of his residual limb is greater than that of Case-1. In terms of arterial changes, Case-1's CSA residual/sound limb ratio of each artery exhibits larger amplitude of change than that of Case-2. One possible explanation for these different trends in muscles and arteries is that, in the process of wearing a prosthesis, the muscle physiological state of residual limb could be maintained as the original mode of operation and the powering ability as far as possible, therefore Case-1's muscles could adjust their own state to decrease the bilateral difference after using a prosthesis. At the same time, her arterial blood flow may regulate the distribution according to the need of the blood supply to each muscle group, so Case-1 shows more obvious arterial diameter fluctuations than Case-2.

In summary, wearing a prosthesis could not only make muscles remodel the movement form and save the physical tension by keeping original body balance and biped gait and increasing the amount of activity, but also maintain the lumen volume of main arteries of residual limb in a certain extent. The arterial blood flow changes may be a kind of adjustment cooperating with the strength and function of the nourished muscles. That is to say, the muscles and blood supply could form a benign interaction, in 
order to prevent disuse atrophy and promote the rehabilitation of residual limb. As for the patients without using a prosthesis, they are prone to long time sitting, greatly reduced standing or walking amount, or gait energy consumption mainly in the sound limb, etc. The cases in this study show overall shrinkage of their residual limb arteries, as well as large extent atrophy of individual muscles. These results may not only cause the function degradation and blood supply issues of residual limb which could form a vicious circle with the muscle atrophy or other residual limb skin and soft tissue problems, but even affect the vascular flow field and various hemodynamic parameters, and afterwards may lead to the arterial lesions that endanger patient's health again. In addition, the significant hypofunction of residual limb could aggravate the burden of sound limb, or involve the sound limb in disuse muscle strength loss.

\section{Conclusion}

From the morphological analysis of eight cases, this study suggests that, the correlation between muscle atrophy and arterial shrinkage of the residual limb of unilateral trans-femoral amputees mainly depends on using a prosthesis or not. The prosthesis users in this study show overall lower extent of both muscle atrophy and arterial shrinkage than the cases without using a prosthesis, and there is a positive correlation between muscle atrophy and arterial shrinkage based on the blood supply relationship which is expressed only in the cases wearing a prosthesis. Therefore, using a prosthesis could not only effectively achieve the functional compensation for residual limb, but also promote the joint adjustments of the whole physiological state of both limbs to adapt to the new gait and body balance, as well as the comprehensive rehabilitation.

\section{Declarations}

\section{Declaration of interest}

The authors report no declarations of interest.

\section{Acknowledgments}

This study is supported by the National Natural Science Foundation of China (11972239\&11772210), the Key projects of the ministry of science and technology of china(2017YFB0702500).

\section{References}

1. Yoo S. Complications following an amputation. Phys Med Rehabil Clin N Am, 2014; 25(1): 169-78.

2. Alvin L Muilenburg and A Bennett Wilson jr. A Manual for Below-Knee Amputees [Internet]. Electronic version. Houston (Texas): Muilenburg Prosthetics and Orthotics. Available from: http://www.oandp.com/resources/patientinfo/manuals/2.htm 
3. Wang M, Li W, Chang GQ, Ye CS, Ou JS, Li XX, Liu Y, Cheang TY, Huang XL, Wang SM. MicroRNA-21 regulates vascular smooth muscle cell function via targeting tropomyosin 1 in arteriosclerosis obliterans of lower extremities. Arterioscler Thromb Vasc Biol, 2011; 31(9): 2044-53.

4. Piazza G, Creager MA. Thromboangiitis obliterans. Circulation, 2010; 121(16): 1858-61.

5. Blevins WA Jr., Schneider PA. Endovascular management of critical limb ischemia. Eur J Vasc Endovasc Surg, 2010; 39(6): 756-61.

6. Shapiro LT, Huang ME. Inpatient rehabilitation of survivors of purpura fulminans with multiple limb amputations: a case series. Arch Phys Med Rehabil, 2009; 90(4): 696-700.

7. Belmont PJ Jr, Davey S, Orr JD, Ochoa LM, Bader JO, Schoenfeld AJ. Risk factors for 30-day postoperative complications and mortality after below-knee amputation: a study of 2,911 patients from the national surgical quality improvement program. J Am Coll Surg, 2011; 213(3): 370-8.

8. Lyon CC, Kulkarni J, Zimerson E, Van Ross E, Beck MH. Skin disorders in amputees. J Am Acad Dermatol, 2000; 42(3): 501-7.

9. Sanders JE, Garbini JL, Leschen JM, Allen MS, Jorgensen JE. A bidirectional load applicator for the investigation of skin response to mechanical stress. IEEE Trans Biomed Eng, 1997; 44(4): 290-6.

10. Portnoy S, Siev-Ner I, Shabshin N, Kristal A, Yizhar Z, Gefen A. Patient-specific analyses of deep tissue loads post transtibial amputation in residual limbs of multiple prosthetic users. J Biomech, 2009; 42(16): 2686-93.

11. Demiralp B, Ege T, Kose O, Yurttas Y, Basbozkurt M. Amputation versus functional reconstruction in the management of complex hind foot injuries caused by land-mine explosions: a long-term retrospective comparison. Eur J Orthop Surg Traumatol, 2014; 24(4): 621-6.

12. Liu K, Tang T, Wang A, Cui S. Surgical revision for stump problems after traumatic above-ankle amputations of the lower extremity. BMC Musculoskelet Disord. 2015; 16: 48.

13. Ypsilantis E, Tang TY. Pre-emptive analgesia for chronic limb pain after amputation for peripheral vascular disease: a systematic review. Ann Vasc Surg. 2010; 24(8): 1139-46.

14. Sanders JE, Fatone S. Residual limb volume change: systematic review of measurement and management. J Rehabil Res Dev, 2011; 48(8): 949-86.

15. Sherk VD, Bemben MG, Bemben DA. Interlimb muscle and fat comparisons in persons with lowerlimb amputation. Arch Phys Med Rehabil, 2010; 91(7): 1077-81.

16. Fraisse, N., et al., Muscles of the below-knee amputees. Ann Readapt Med Phys, 2008. 51(3): p. 21827.

17. Schmalz, T., S. Blumentritt, and C.D. Reimers, Selective thigh muscle atrophy in trans-tibial amputees: an ultrasonographic study. Arch Orthop Trauma Surg, 2001. 121(6): p. 307-12.

\section{Figures}



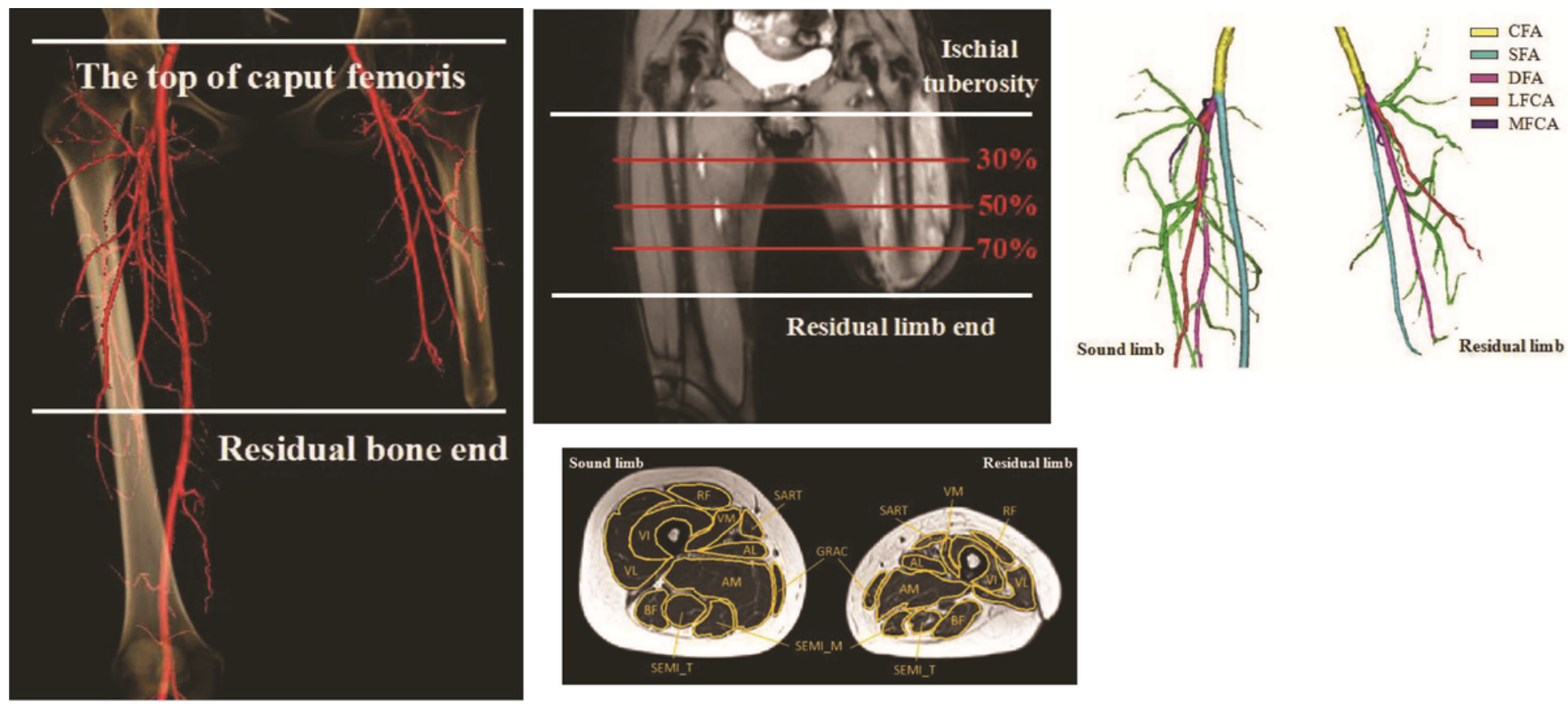

Figure 1

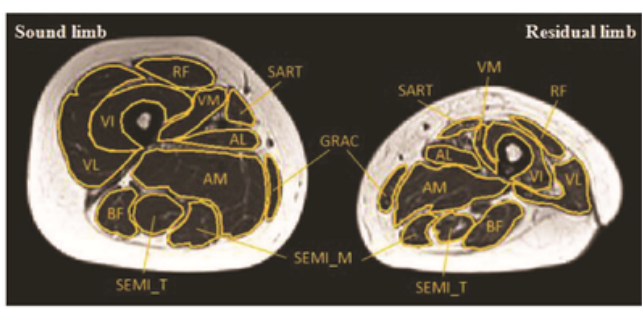

(a) 3D reconstruction model of the arterial trees of residual limb and sound limb (front view). The measurement area of both thighs was defined from the top of caput femoris to residual bone end. (b) The coronal MRI image shows selected horizontal slices at three different levels, $30 \%, 50 \%$ and $70 \%$ of the residual limb length which is from ischial tuberosity to the residual limb end. (c) The vascular research objectives: 5 main arteries. (d) The 11 selected muscle measurement objectives.
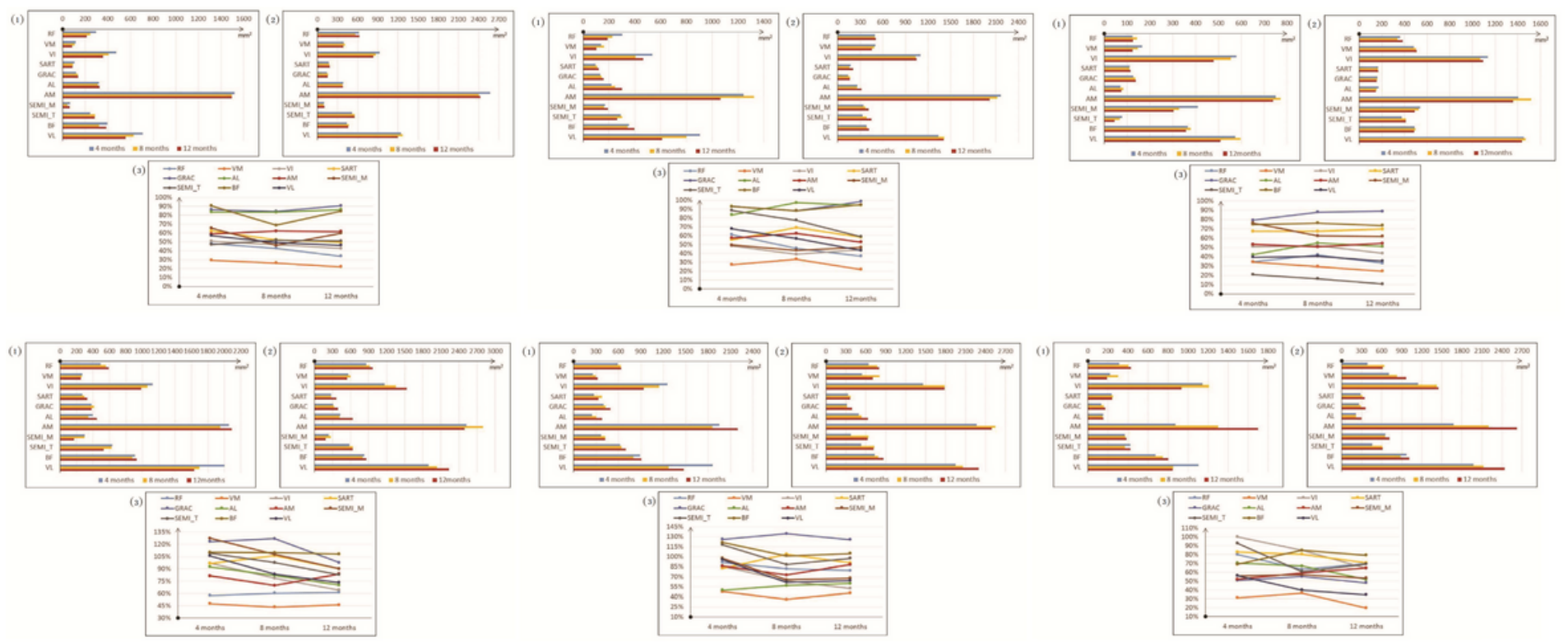

Figure 2

Case-1 and Case-2's follow up measurement results of the muscle CSA. (a) Case-1 at upper level (30\%); (b)Case-1 at upper level (50\%); (c)Case-1 at upper level (70\%); (d)Case-2 at upper level (30\%); (e) Case-2 at 
upper level (50\%) ; (f) Case-2 at upper level (70\%) . (1) residual limb; (2) sound limb; (3) residual/sound limb ratio.
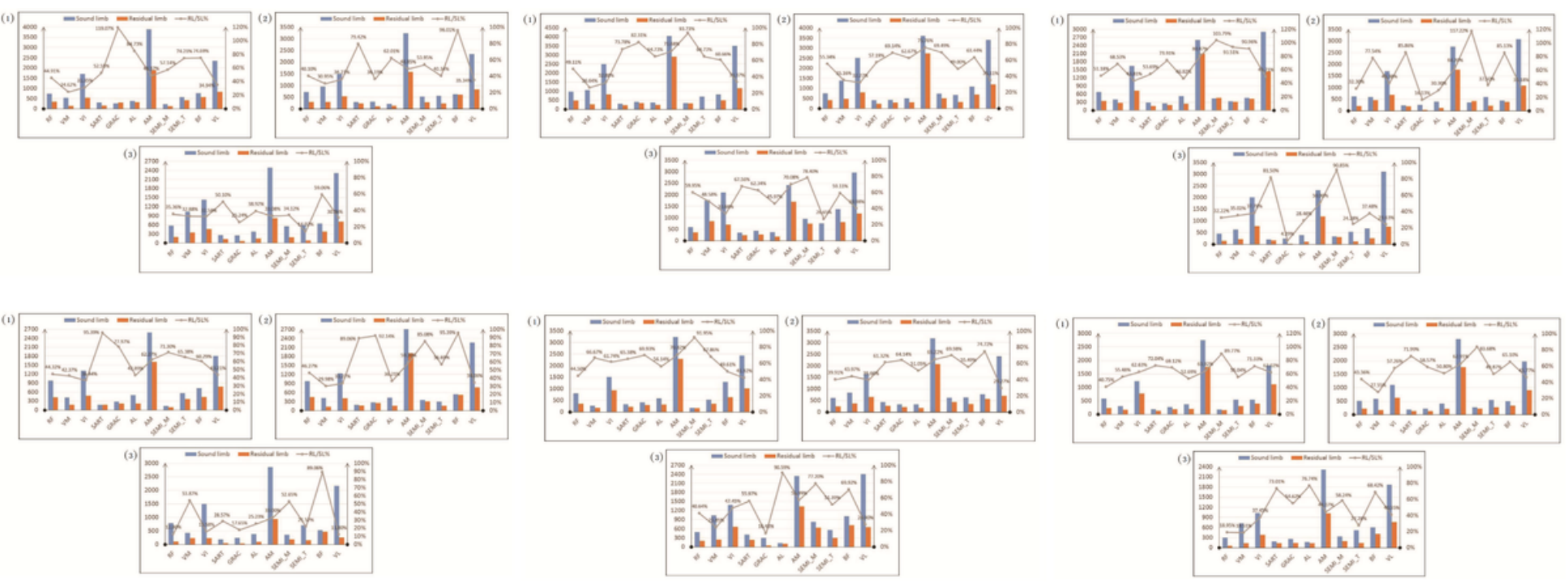

\section{Figure 3}

Case-3 Case-8's measurement results of the bilateral muscle CSA and the residual/sound limb ratio. (1) upper level (30\%); (2) middle level (50\%); (3) lower level (70\%). (a) Case-3; (b) Case-4; (c) Case-5; (d) Case6; (e) Case-7; (f) Case-8.
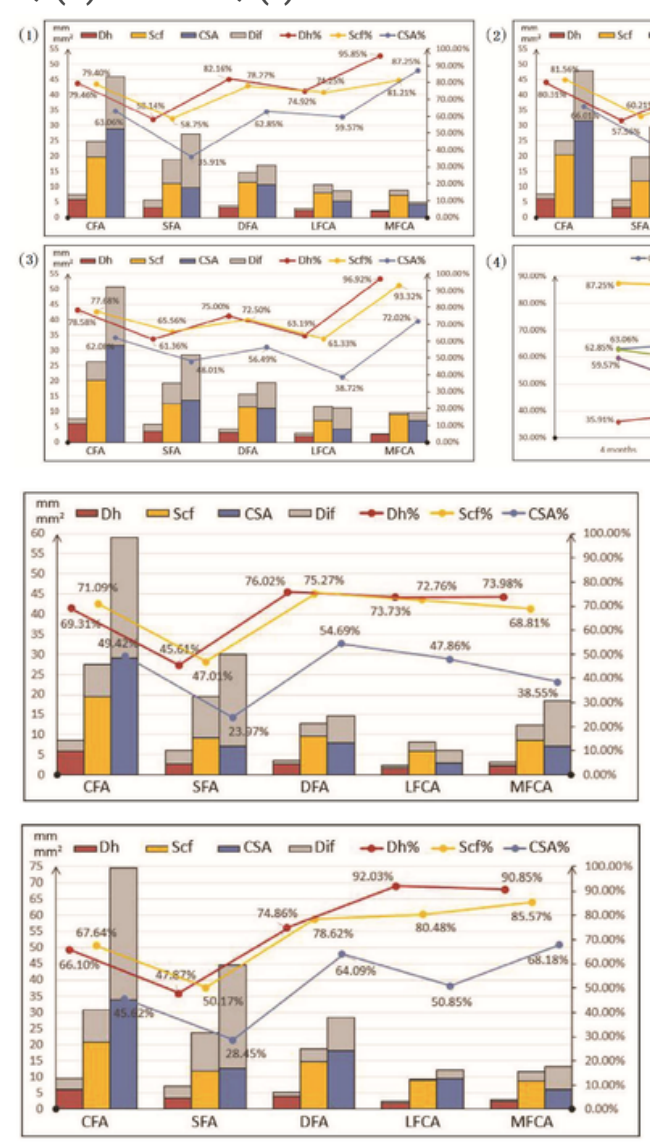
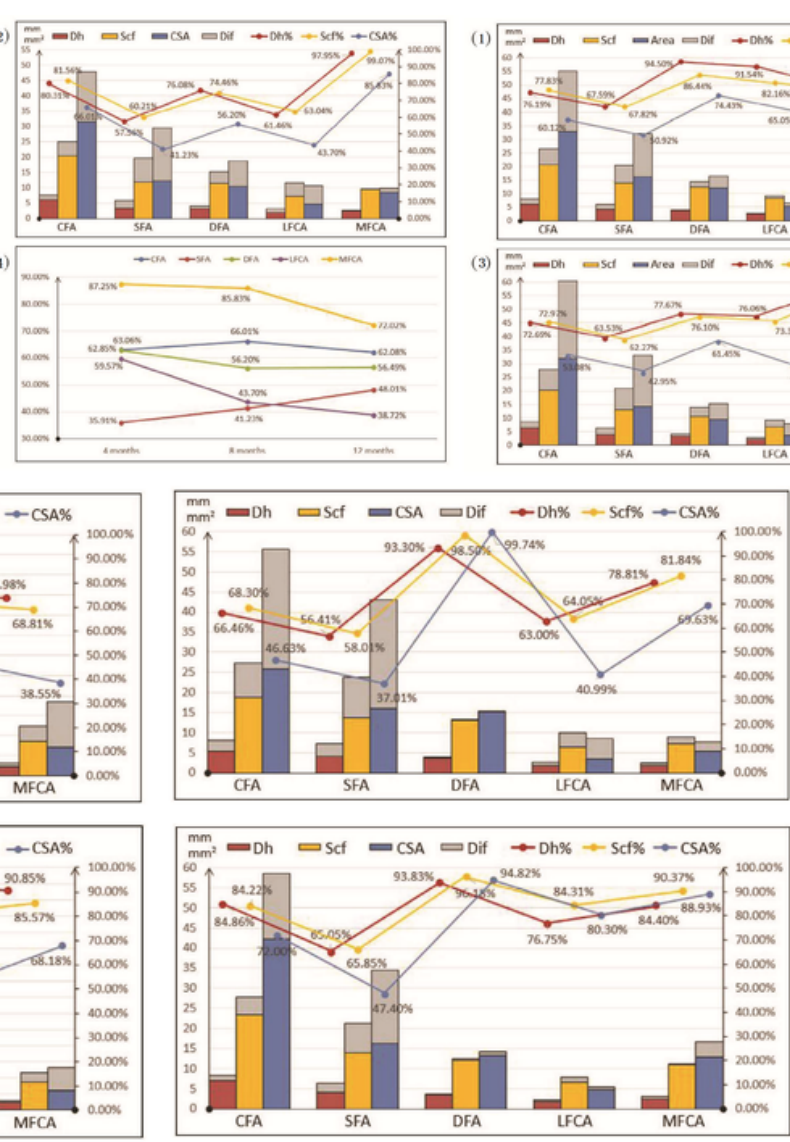
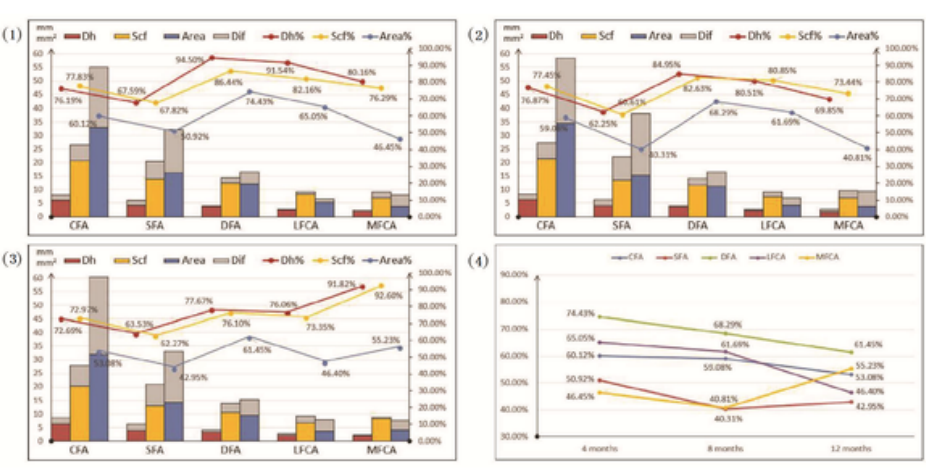

\section{Figure 4}


Case-1 Case-8's measurement results of the 5 main arteries. (1) 4 months after surgery; (b) 8 months after surgery; (2) 12 months after surgery; (3) CSA\% changes during follow-up period. (a) Case-1; (b) Case-2; (c) Case-3; (d) Case-4; (e) Case-5; (f) Case-6; (g) Case-7; (h) Case-8. 